\title{
Parametric Study on Buckling Behavior of Aluminum Alloy Thin-Walled Lipped Channel Beam with Perforations Subjected to Combined Loading
}

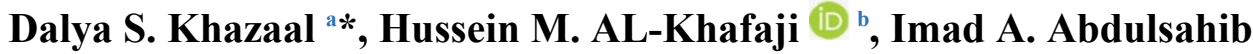 \\ ${ }^{a}$ Mechanical Engineering Department, University of Technology, Baghdad, Iraq. \\ me.19.18@grad.uotechnology.edu.iq \\ ${ }^{\mathrm{b}}$ Mechanical Engineering Department, University of Technology, Baghdad, Iraq. \\ 20188@uotechnology.edu.iq \\ ${ }^{c}$ Mechanical Engineering Department, University of Technology, Baghdad, Iraq. \\ 20018@,uotechnology.edu.iq \\ *Corresponding author.
}

Submitted: 16/05/2020

Accepted: 09/07/2020

Published: 25/01/2021

\section{K E Y W O R D S}

Buckling, lipped beam, nonlinear finite elements, perforation, Thin-walled structure, Taguchi method

\begin{abstract}
A B S T R A C T
The objective of the research presented in this paper is to investigate the buckling behavior of a perforated thin-walled lipped channel beam subjected to combined load. A nonlinear finite element method was used to analyze the buckling behavior of the beam. Experimental tests were made to validate the finite element simulation. Three factors with three levels for each factor were chosen to examine their influence on the buckling behavior of the beam and these factors are: the shape of holes, opening ratio $D / D_{O}$ and the spacing ratio of $S / D_{O}$. The finite elements outcome was analyzed by using Taguchi method to identify the best set of threeparameter combinations for optimum critical buckling load. The analysis of variance technique (ANOVA) was implemented to determine the contribution of each parameter on buckling strength. Results showed that the mode of buckling failure of the perforated beam is lateral-torsional buckling and the hexagonal hole shape, $D / D_{O}=1.7$ and $S / D_{O}=1.3$ were the best combination of parameters that gives the best buckling strength. The results also showed that the shape of holes is the most influential on buckling behavior of the perforated beam for this case of loading.
\end{abstract}

How to cite this article: D. S. Khazaal, H. M. Al-Khafaji and I. A. Abdulsahib, "Parametric study on buckling behavior of aluminum alloy thin-walled lipped channel beam with perforations subjected to combined loading," Engineering and Technology Journal, Vol. 39, Part A, No. 01, pp. 89-103, 2021.

DOI: https://doi.org/10.30684/etj.v39i1A.1710 This is an open access article under the CC BY 4.0 license http://creativecommons.org/licenses/by/4.0 


\section{INTRODUCTION}

Aluminum alloy members are being used increasingly for structural applications. They are used in space structures, curtain walls, and bridges. The advantages of using aluminum alloy as a structural material are many, such as lightness, high strength to weight ratio, better corrosion resistance, and ease of production. Nowadays, perforations are commonly introduced in structural members for minimizing the weight of structures and to facilitate the building services like electric wiring, piping, plumbing, heating, and cooling conduits and maintenance works. These perforations cause a redistribution of stresses near the perforation area that may vary the elastic stiffness and ultimate load of the structural member. The number of perforations, size, shape, and location greatly affect the behavior of the perforated structural members. The buckling behavior of perforated structural members has been studied by a large number of researchers. Moen and Shafer [1-3] investigated the impact of slotted holes on the buckling behavior of cold-formed steel columns. Zhou and Young [4] investigated the buckling behavior of 6061-T6 aluminum alloy square hollow sections (SHS) with a circular hole under web crippling. They presented 84 test results and 132 numerical results. Macdonald et al. [5, 6] studied experimentally and numerically the effect of different shapes and arrangements of perforation on the load capacity of perforated cold-formed steel columns with lipped channel cross-section. The authors also investigated the effect of end conditions and compression loading on the load capacity of these columns [7, 8]. Feng and Young [9] studied the failure of SHS stub columns with circular holes under compression load and made a comparison between the test results and design strength using the current design rules for steel structural members with perforations. Bhavi [10] Made a comparison between buckling strength of perforated cold-formed stainless steel and aluminum alloy subjected to compressive load using open lipped channel cross-sections. A finite element analysis using ANSYS software was developed and its accuracy was validated using the experimental results. Feng et al.[11] tested a total of 64 specimens of 6061-T6 and 6063-T5 aluminum alloy perforated SHS and RHS under axial compression loading and results were compared with the Design strength method. Ferreira and Martins studied numerically the lateral-torsional buckling of cellular beams under three loading types: uniformly distributed load, mid-span concentrated load, and uniform bending [12,13]. Material and geometrical nonlinearity were used in the nonlinear buckling analysis. Yu et al. [14] presented a numerical and analytical study on the distortional buckling behavior of a thin-walled lipped channel steel beam with circular perforations under uniformly distributed transverse loads. Shamass and Guarracino used analytical and numerical analyses in studying the web-post buckling behavior of normal and high strength steel cellular beams under bending load [15]. Bolukbas and Mete [16] investigated experimentally and numerically the effect of elliptic perforation on the buckling behavior of (CHS) columns under axial compression. Bahrami and Najarnasab [17] presented the ultimate behavior of steel plate girders with circular perforations under shear loading. A different shape, number, and arrangement of holes were used in the analysis. Little investigations are being carried out on the behavior and design of thin-walled structural members under combined loading. White et al. [18] studied experimentally and analytically the maximum strength of square-section thin-walled beam subjected to combined torsion and bending loading. Mohri et al. [19] investigated analytically the lateral buckling of thin-walled I-section beam-column under combined axial compression and bending loading. Cheng et al. [20] presented an analytical investigation on the lateral-torsional buckling of cold-formed steel with channel sections subjected to combined bending and compression loading. One of the optimization methods is Taguchi technique that uses a signal to noise $(\mathrm{S} / \mathrm{N})$ ratio, an orthogonal array, and analysis of variance (ANOVA) to find the best set of parameters and the most influential on buckling strength. Taguchi can be used for reducing the cost and time required to perform the experiments [21-26]. There is very little research which investigated the effect of holes on the buckling strength of a cantilever beams. This work presented a new way of applying the loads and it examines the buckling behavior of the cantilevers in the manner of a parametric study. Therefore, In this study, an experimental and numerical investigation was presented to study the buckling behavior for 6061-O aluminum alloy thin-walled lipped channel beam with perforations on the web subjected to combined load. Three factors namely; shape of holes, opening ratio $D / D_{O}$ and spacing ratio $S / D_{O}$ with three levels for each factor were chosen to examine their influence on buckling behavior of the beam. Taguchi method was applied to check and find the optimum set of 
parameters that afford the best strength of buckling. Furthermore, the analysis of variance technique (ANOVA) was employed to determine the most effective parameter on the critical load of buckling.

\section{TAgUCHI AND ANOVA TECHNIQUE}

Taguchi technique is dependent on conducting experiments to check the affectability of response variables to a combination of control parameters by using an orthogonal array to achieve the best set of the control parameters. In this work, the Taguchi method is used to find the effect of the input factors on the final output. A signal to noise ratio $(\mathrm{S} / \mathrm{N})$ was used in the analysis of experimental results to define the best process designs. The technique of Taguchi is a powerful tool of design experiments for high-quality systems design and to analyze the effect of control parameters over the output variable. The log functions of required output are called the signal to noise ratios $(\mathrm{S} / \mathrm{N})$, which is the objective functions for optimization, help in the prediction of optimum results. There are three standard types of SN ratio; higher the better (HB), lower the better (LB), and Nominal the best (NB). The higher buckling strength is required, therefore, the higher the better formula is used[27]:

$$
S / N=-10 \log \left(\frac{1}{n} \sum_{i=1}^{n} \frac{1}{y_{i}^{2}}\right)
$$

Where, $y_{i}$ is the read data and $n$ is the number of observations. In this study, the shape of holes, opening ratio $\left(D / D_{O}\right)$ and spacing ratio $\left(S / D_{O}\right)$ are chosen as input factors to determine the most effective factor to reach the higher buckling strength. The three factors given above with three various levels were chosen for the experimental design. These factors and levels are given in Table I and the number of experiments is $27(3 * 3 * 3)$ by using this method. This work aims to identify the most influential factors to obtain the higher buckling strength for the thin-walled member and to find the optimum set of parameters with a limited number of experiments.

TABLE I: Factors and levels

\begin{tabular}{ccccc}
\hline \hline \multirow{2}{*}{ symbols } & parameter & \multicolumn{2}{c}{ Levels } \\
\cline { 3 - 5 } & & Level 1 & Level 2 & Level 3 \\
\cline { 3 - 5 } $\mathrm{A}$ & Shape of holes & Hexagonal & Circular & square \\
\hline $\mathrm{B}$ & $D / D_{O}$ & 1.7 & 1.6 & 1.5 \\
\hline $\mathrm{C}$ & $S / D_{O}$ & 1.5 & 1.4 & 1.3 \\
\hline
\end{tabular}

\section{ANALYSIS OF VARIANCE (ANOVA)}

Analysis of variance (ANOVA) is a powerful statistical technique, which specifies the important parameters and demonstrates the percentage contribution of each parameter. In this research, the ratio $(\mathrm{S} / \mathrm{N})$ was used for making the decision. The technique of ANOVA is based on the total sum of squared deviations (SST) which is equal to[28]:

$$
S S_{T}=\sum_{i=1}^{n}\left(n_{i}-n_{m}\right)^{2}
$$

The percentage of contribution $P$ could be calculated as:

$$
\begin{gathered}
P=\frac{s S_{d}}{S S_{T}} \\
\text { d.o.f of any parameter }(\text { factor })=k-1 \\
\text { Total d.o.f }=n-1 \\
\text { d.o.f of error = total d.o.f }-\sum \text { d.o.f of parameters } \\
V=\frac{s S_{d}}{\text { d.o.f }} \\
F=\frac{V}{V_{E}}
\end{gathered}
$$


Where:

$n$ : The number of observations (trails) in the orthogonal array.

$n_{i}$ : mean $\mathrm{S} / \mathrm{N}$ ratio for the ith observation.

$n_{m}$ : mean of all parameters.

$S S_{d}$ : A sum of the squared deviations.

$K:$ The number of levels for each parameter.

$P$ : Contribution's percentage.

$V$ : Parameter's (factor) variance.

$V_{E}$ : Error's variance.

d. o.f: A degree of freedom.

$F: F$ - test, which is an indicator of the quality characteristic of the process.

\section{EXPERIMENTAL PROGRAM}

\section{Material properties}

Aluminum alloy $6061-\mathrm{O}$ sheets with $1.6 \mathrm{~mm}$ thickness were used to manufacture the specimens. Tensile tests were conducted to validate the mechanical properties of sheets. Tests were done on the tensile specimens with dimensions according to ASTM specifications B557M-02a [29] as indicated in Figure 1 and Table II whereas Table III lists test results.
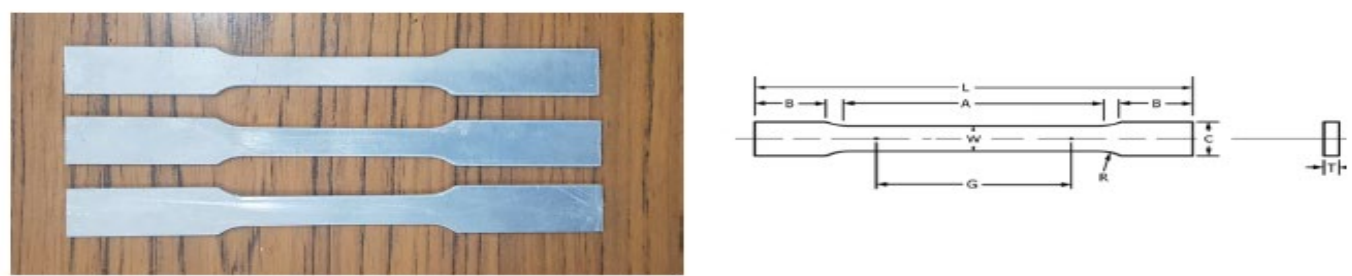

Figure 1: tensile test specimens

TABLE II: Dimensions of tensile test specimen (mm)

\begin{tabular}{cc}
\hline \hline G-Gage length & 57 \\
\hline W-Width & 12. \\
& 5 \\
\hline T-Thickness & 1.6 \\
\hline R-Radius of fillet & 12. \\
& 5 \\
\hline A-Length of reduced section & 60 \\
\hline L-Overall length & 180 \\
\hline B-Length of the grip section & 50 \\
\hline C-Width of the grip section & 20 \\
\hline
\end{tabular}

TABLE III:

The Mechanical Properties of Aluminum alloy 6061-O

\begin{tabular}{cccccc}
\hline \hline Aluminum 6061-O & Young & Poisson & Yield & Ultimate & Fractu \\
modulu & 's & stress & ress \\
& $\mathbf{S}$ & ratio & $\boldsymbol{\sigma}_{\mathbf{y}}(\mathbf{M p a})$ & $\boldsymbol{\sigma}_{\mathbf{u}}(\mathbf{M p a})$ & $\begin{array}{c}\text { stress } \\
\boldsymbol{\sigma}_{\mathbf{f}} \\
(\mathbf{M p a})\end{array}$ \\
\hline $\begin{array}{c}\text { Experimental measured } \\
\text { (average of three specimens) }\end{array}$ & 68.9 & 0.33 & 50 & 109 & 98 \\
\hline
\end{tabular}




\section{Specimen geometry}

The cross-section dimensions designed according to the design constraints of Eurocode (EN1993-1-3) [30] as shown in Figure 2. The beam free length is assumed to be $(500 \mathrm{~mm})$ for all specimens.

$$
\begin{gathered}
b / t \leq 60, a / t \leq 50, h / t \leq 500 \\
0.2 \leq a / b \leq 0.6 \\
a \leq 25
\end{gathered}
$$

Where, $h$ is the cross-section depth, $t$ is the thickness, $b$ is the flange width and $a$ is the lip width.

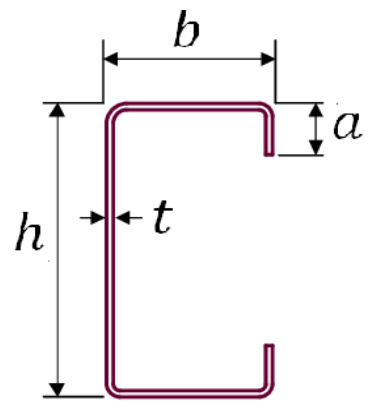

\begin{tabular}{c|c}
\hline \multicolumn{2}{c}{ Cross-section } \\
\hline$h(\mathrm{~mm})$ & 100 \\
$b(\mathrm{~mm})$ & 38 \\
$a(\mathrm{~mm})$ & 12 \\
$t(\mathrm{~mm})$ & 1.6 \\
\hline
\end{tabular}

Figure 2: Specimen cross-section dimensions

In this work, three shapes of holes designed to be made in the web as shown in Figure 3 with dimensions according to the limits of applicability of web holes of a cellular beam in Eurocode (BS5950) [31] :

$$
\begin{gathered}
1.25<D / D_{O}<1.75 \\
1.08<S / D_{O}<1.5
\end{gathered}
$$

Where, $D$ is the web depth, $D_{O}$ is the hole depth and $S$ is the space between holes centers.

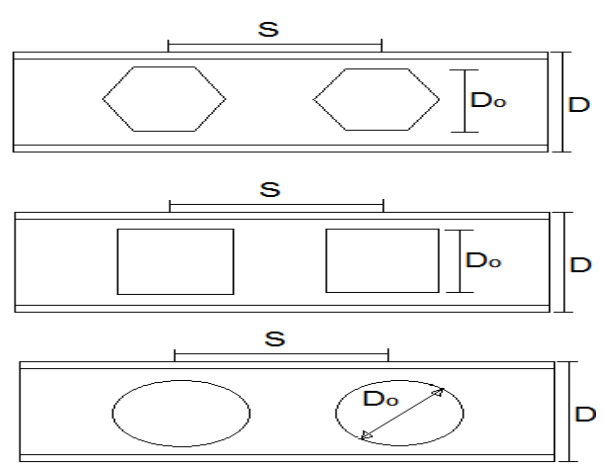

Figure 3: Type of hole shapes

\section{Specimen preparing}

. A total of four specimens were tested in this work to verify the numerical solution. One of them without holes as a reference beam and the other three specimens had five holes with shapes of (hexagonal, circular, and square) as shown in Figure 4. The cross-section of lipped beams was made by flexing the Aluminum alloy 6061-O sheet. A water jet process was used to make holes on the web of the beam to get a good surface finishing and to minimize any residual stresses at the area of the holes. This type of punching prevents any generation of heat due to the cutting process, which can change the material properties in the hole's area. Two solid cubes of Teflon with dimensions $(96.5 * 34.5 * 20) \mathrm{mm}^{3}$ and $(96.5 * 34.5 * 50) \mathrm{mm}^{3}$ were mounted at the two ends of the beam to prevent 
any local deformation and distortion of a cross-section at points where load acting and at beam fixing. The specimens were fixed by using a fixture stand as shown in Figure 5. The angle of inclination of the fixture stand was chosen to be $45^{\circ}$ in order to achieve equal initial loads of compression and bending as explained in the next section.

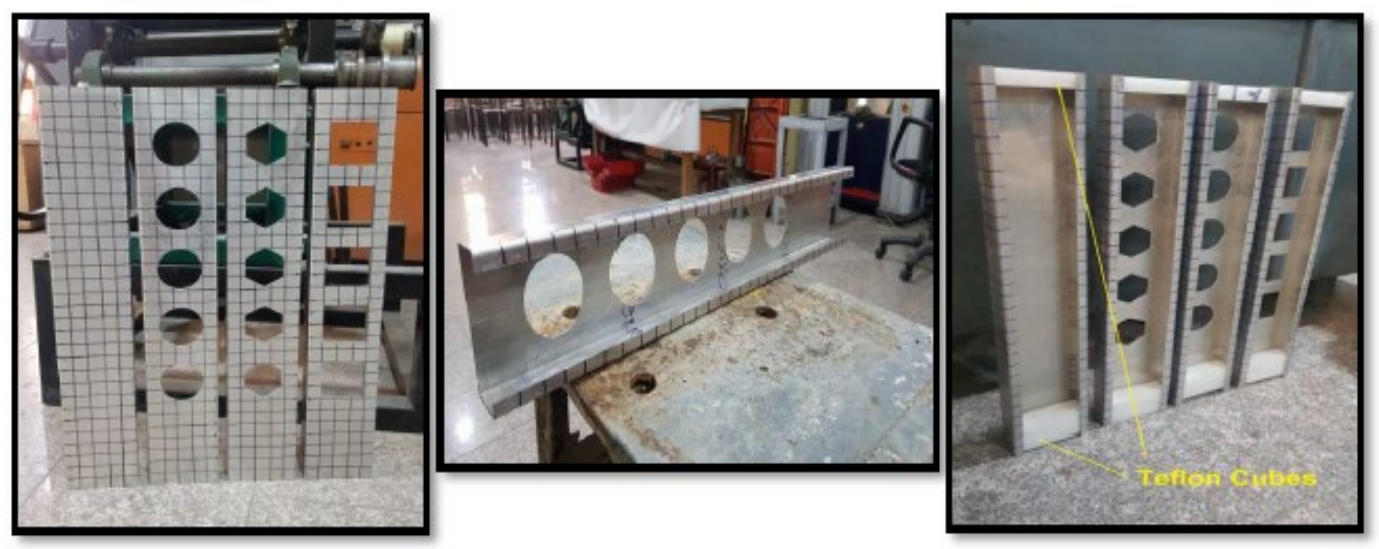

Figure 4: Test specimens

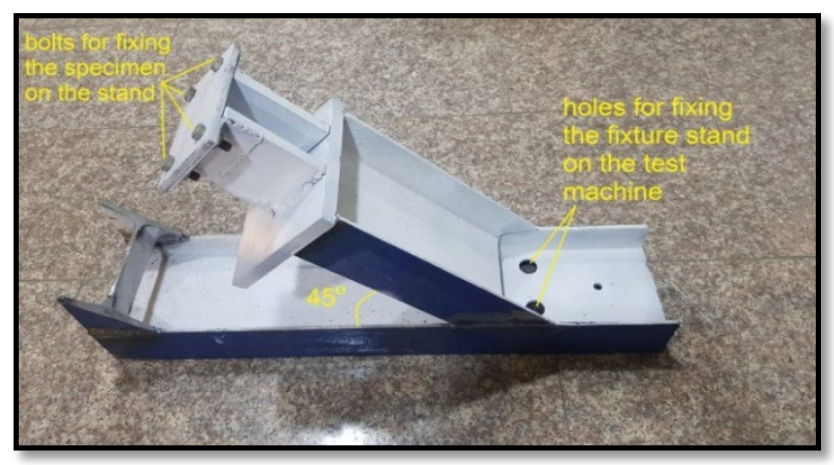

Figure 5: the fixture stand of test specimens

\section{Buckling test}

The WDW-200E Computer Controlled Electronic Universal Testing Machine was used for testing the specimens for buckling failure under combined loading. Four specimens of thin-walled lipped channel beam were tested under combined bending and compression loading by applying an inclined force on the upper edge of the free end of the cantilever beam. This force can be resolved into two components; one is vertical acting as bending force and the other is horizontal and acting as compression force. Because of the difficulty of applying such force by the used machine, it has been suggested that the specimen would be inclined and the force would be applied vertically on it so that the required inclination can be achieved as shown in Figure 6. The load was applied gradually at a rate of $3 \mathrm{~mm} / \mathrm{min}$ at the upper edge of the free end of the cantilever. This low speed of loading is sufficient to be considered as a static load. The test readings were directly recorded and the loaddisplacement curves were obtained. The average time taken for each test was approximately ten minutes. 

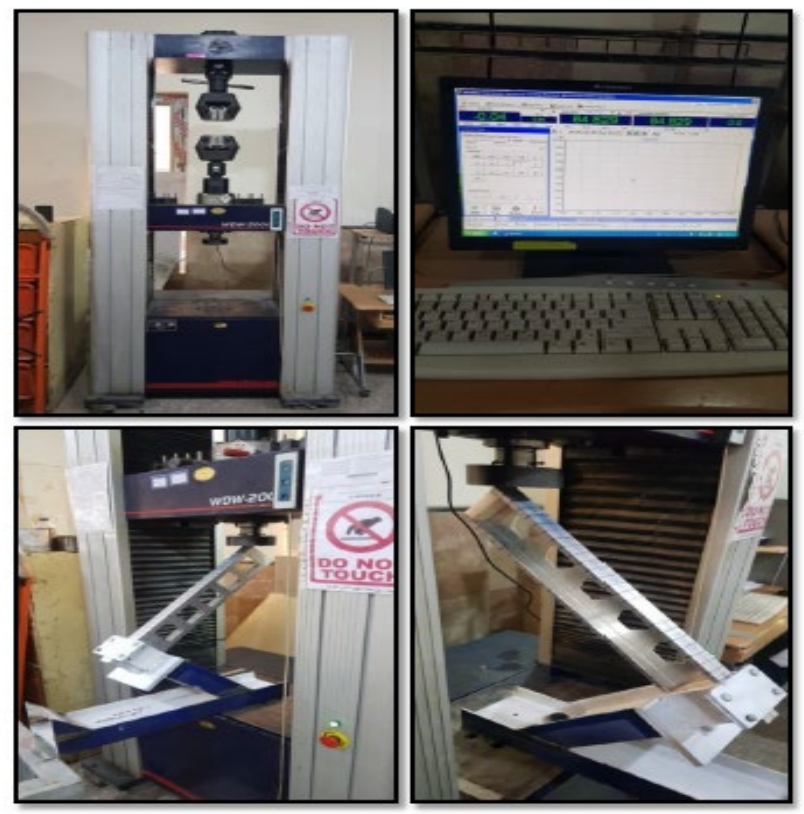

Figure 6: Buckling test under combined loading

\section{Finite Element Analysis}

Finite element analysis is a powerful tool that can be used for a wide range of applications, like aluminum structures. FEM provides many advantages over physical experiments, especially when a parametric study is involved. It is inexpensive and time-efficient. The finite element approach is capable to predict the ultimate strengths and failure modes of aluminum members provided that the finite element model is reliable. Therefore, it is very necessary to verify the model against experimental tests. While the eigenvalue buckling analysis doesn't describe the actual behavior of the structure and it does not give accurate results, the nonlinear analysis will be used in the present work. The target of the nonlinear finite element analysis is mainly to determine the ultimate capacity of the structure which can be defined as the collapse load, i.e. the maximum load that the structure can withstand.

\section{Modeling}

ANSYS 15 software was used to model and analyze perforated beams by finite element analysis using SHELL181. It is defined by four nodes having six degrees of freedom at each node, translations in the $\mathrm{x}, \mathrm{y}$, and $\mathrm{z}$ directions, and rotations about the $\mathrm{x}, \mathrm{y}$, and $\mathrm{z}$-axes as shown in Figure 7. SHELL181 is well-suited for linear, large rotation, and/or large strain nonlinear applications [32]. Figure 8 shows the models of the beams with different shapes of holes. To prevent flange deformation at where the load was acting; a solid cube of $(96.5 * 34.5 * 20) \mathrm{mm}^{3}$ in dimension was presented between the upper and lower flanges at the free end of the beam. The cube and the beam are assumed to be made from the same material. The model is a cantilever beam so, one end is fixed and the other free. The force $\mathrm{F}$ is applied in the downward direction on the top edge of the free end with an inclination of $45^{\circ}$ as shown in Figure 9.

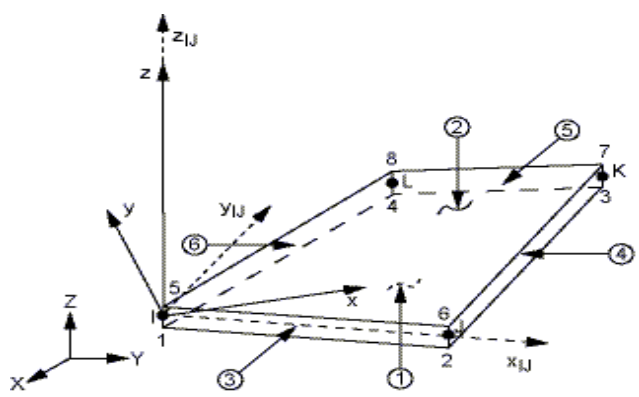

Figure 7: SHELL181 geometry 

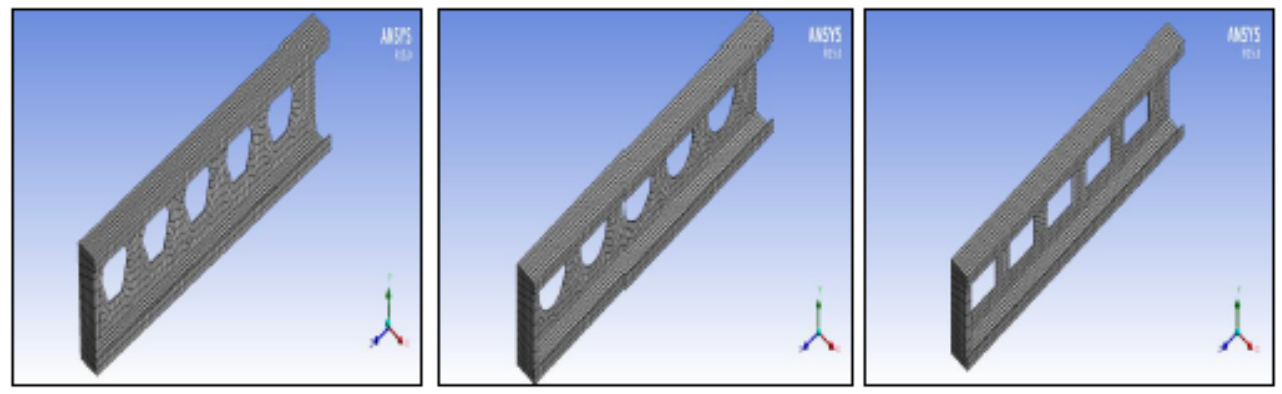

Figure 8: Models of the beam

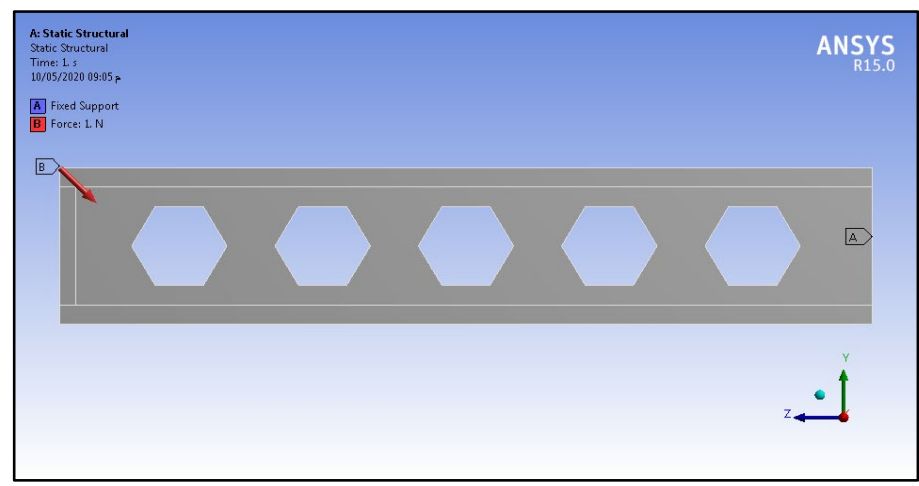

Figure 9: Load and boundary condition

\section{Convergence study}

The mesh convergence was established for the reference beam (without holes) by increased mesh density in each part of the model. It was observed that there were no considerable differences in load response between $10 \mathrm{~mm}$ and $5 \mathrm{~mm}$ elements but the processing time was considerable and any increment in mesh density is unnecessary as shown in Figure 10. Therefore, $10 \mathrm{~mm}$ Element size was used in subsequent analysis with 3322 number of elements.

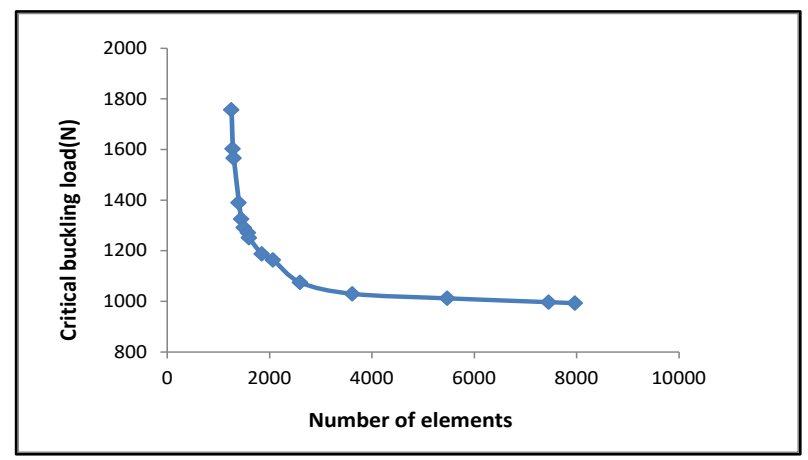

Figure 10: Critical buckling load against Number of elements (mesh density)

\section{RESULTS}

\section{Test Results}

Figure 11 demonstrates the load-displacement curves obtained from the experimental test and the results of the critical buckling load were indicated in Table IV. The experimental results showed that the buckling strength of the thin-walled beam decreases with the presence of holes on the web when subjected to combined loading. 
TABLE IV:Specimens hole dimensions and experimental results

\begin{tabular}{cccc}
\hline \hline Shape of holes & $\boldsymbol{D}$ & $\boldsymbol{S}$ & $\boldsymbol{P}_{\boldsymbol{E X P}}(\mathbf{N})$ \\
& $\boldsymbol{D}_{\boldsymbol{o}}$ & $\boldsymbol{D}_{\boldsymbol{o}}$ & \\
\hline Without holes (Ref.) & ---- & ---- & 998 \\
\hline Hexagonal & 1.7 & 1.5 & 825 \\
\hline Circular & 1.7 & 1.5 & 801.5 \\
\hline Square & 1.7 & 1.5 & 633 \\
\hline
\end{tabular}
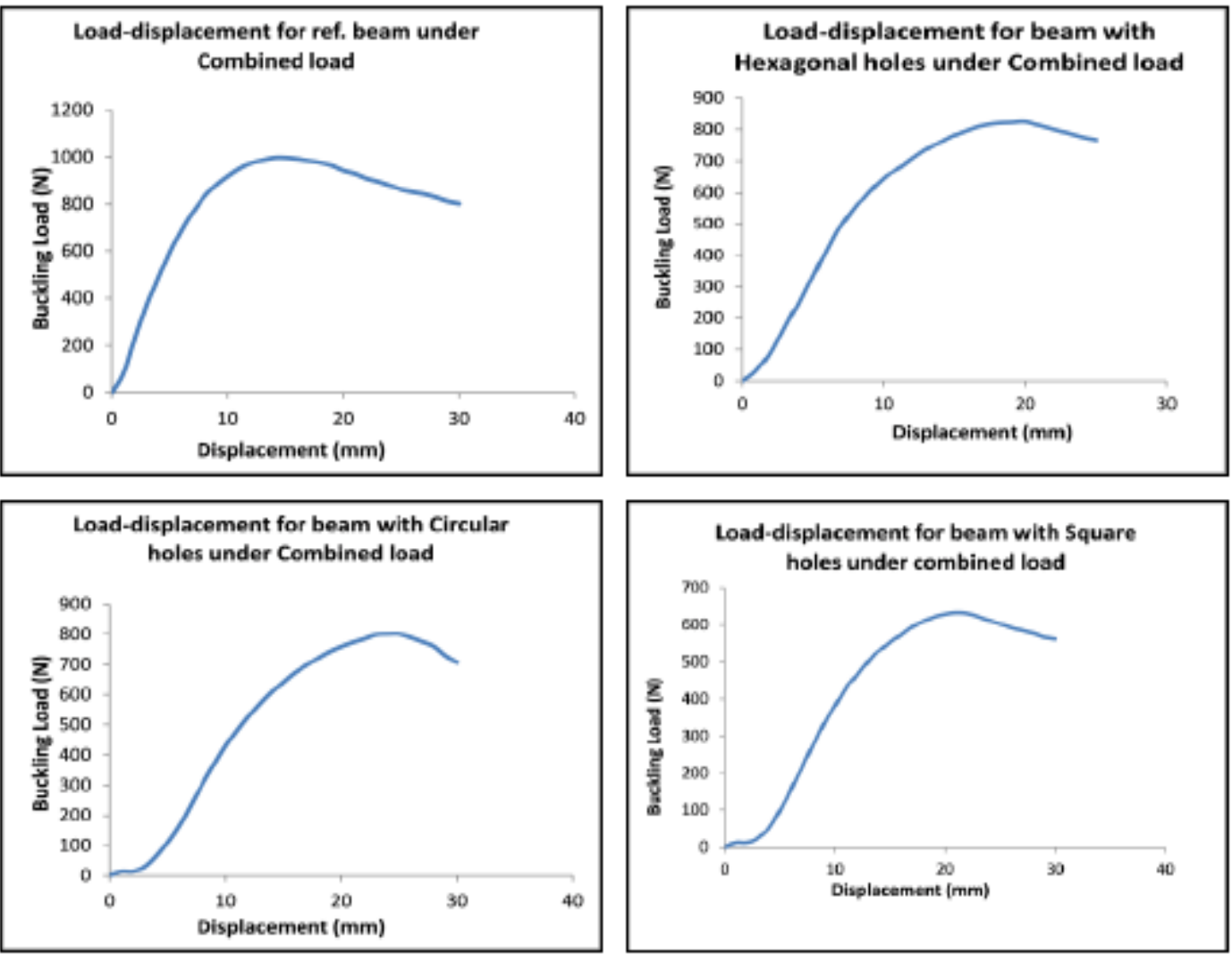

Figure 11: The load-displacement curves for beams under compression load

\section{Validation of FEM Results using the Experimental Results}

The ANSYS version (15) analysis gave a good agreement with the experimental results. Table V and Figure 12 show a comparison of the effect of holes on the ultimate load between numerical and experimental results. A comparison of Load-displacement curves between the experimental and the numerical results were shown in Figure 13. Figure 14 shows the lateral-torsional buckling failure for the perforated lipped channel beam.

TABLE V: Numerical and experimental results of ultimate load

\begin{tabular}{ccccccc}
\hline \hline $\begin{array}{c}\text { Shape of } \\
\text { holes }\end{array}$ & $\boldsymbol{D} / \boldsymbol{D}_{\boldsymbol{O}}$ & $\boldsymbol{S} / \boldsymbol{D}_{\boldsymbol{O}}$ & $\begin{array}{c}\boldsymbol{P}_{\text {EXP }} \\
(\mathbf{N})\end{array}$ & $\begin{array}{c}\boldsymbol{P}_{\text {FEM }} \\
(\mathbf{N})\end{array}$ & $\mathbf{P}_{\text {FEM }} / \mathbf{P}_{\text {EXP }}$ & $\begin{array}{c}\text { Percent error } \\
\mathbf{\%}\end{array}$ \\
\hline Without holes & ---- & ---- & 998 & 1030 & 1.0321 & 3.1 \\
\hline Hexagonal & 1.7 & 1.5 & 825 & 848.56 & 1.0286 & 2.78 \\
\hline Circular & 1.7 & 1.5 & 801.5 & 825.34 & 1.0297 & 2.89 \\
\hline Square & 1.7 & 1.5 & 633 & 647 & 1.0221 & 2.16 \\
\hline
\end{tabular}




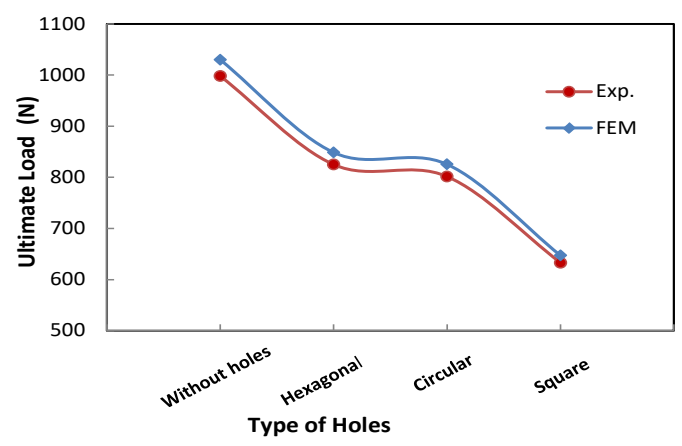

Figure 12: Comparison of effect of holes on ultimate load between numerical and experimental results
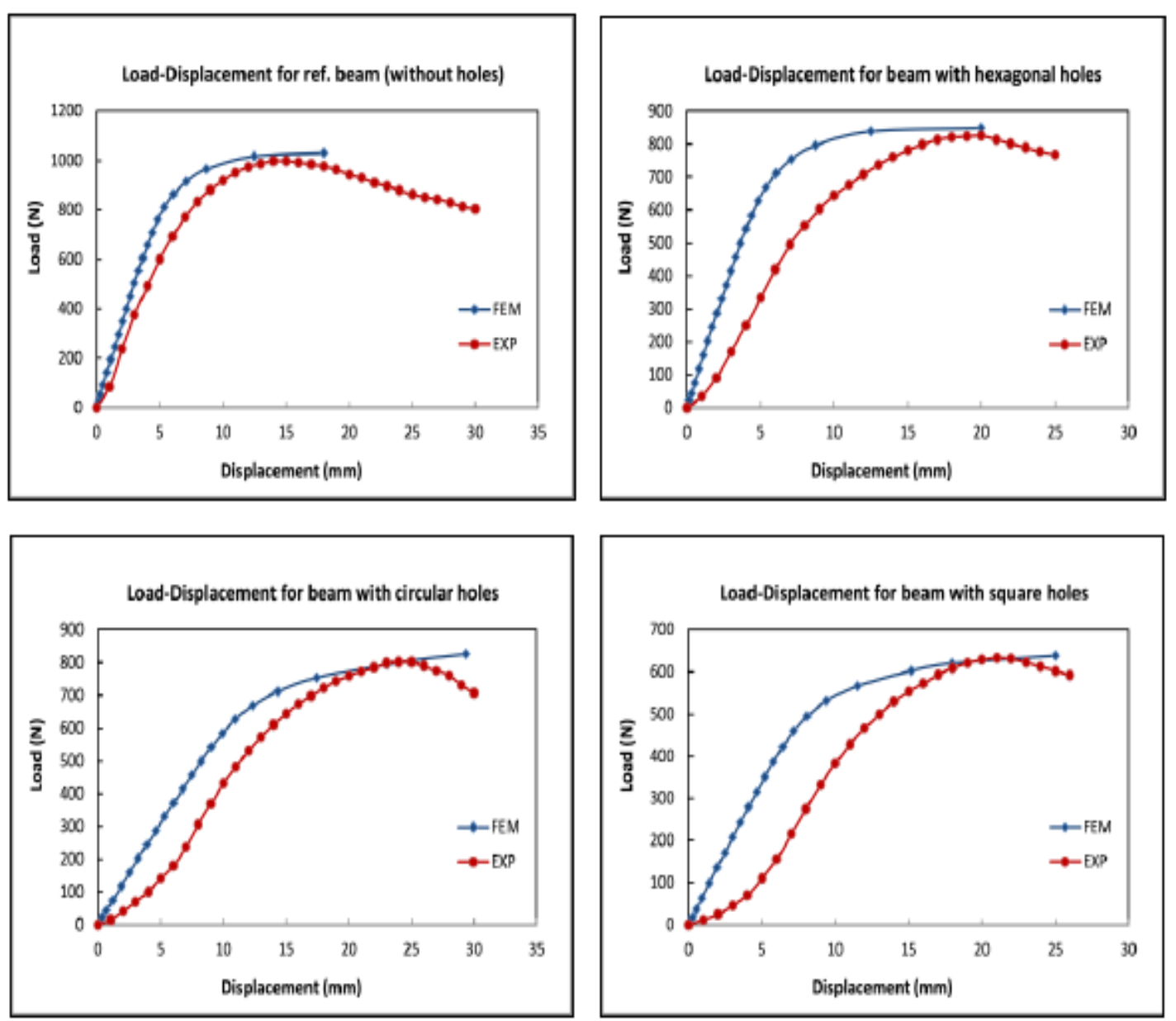

Figure 13: numerical and experimental load-displacement curves for each type of holes 

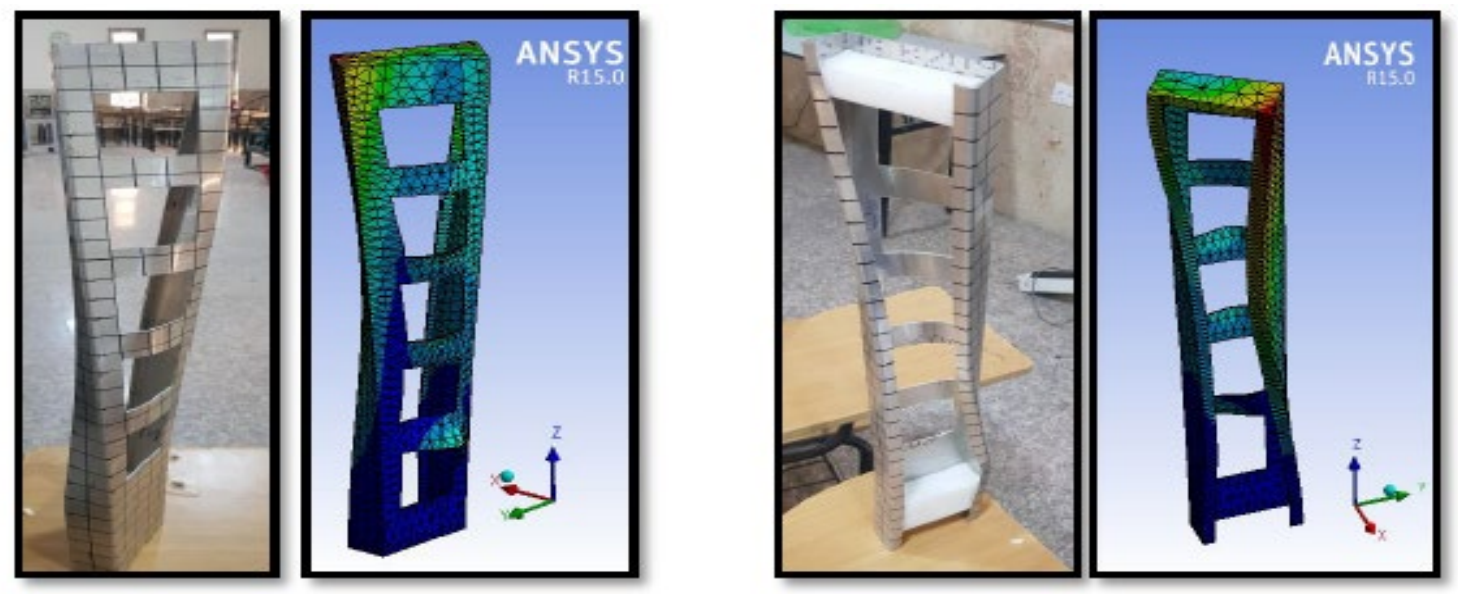

Figure 14: The lateral-torsional buckling failure

\section{Finite element Results}

Nonlinear finite element analyses were performed to calculate the ultimate load. In this study, the strength-to-weight ratio was used for the optimization process due to its importance in the lightweight structures especially with the exist of perforators According to three parameters and three levels, an orthogonal array L27 was established, as presented in Table VII. So, the twenty-seven value of ultimate load was got from different combinations of parameters' levels.

TABLE VI:Orthogonal array for levels combinations and corresponding ultimate load

\begin{tabular}{ccccccc}
\hline \hline $\begin{array}{c}\text { No. of } \\
\text { test }\end{array}$ & $\begin{array}{c}\text { Shape of } \\
\text { holes }\end{array}$ & $\begin{array}{c}\text { Opening } \\
\text { ratio } \\
\left(\boldsymbol{D} / \boldsymbol{D}_{\boldsymbol{O}}\right)\end{array}$ & $\begin{array}{c}\text { Spacing } \\
\text { ratio } \\
\left(\boldsymbol{S} / \boldsymbol{D}_{\boldsymbol{o}}\right)\end{array}$ & $\begin{array}{c}\text { Ultimate } \\
\text { load }(\mathbf{N})\end{array}$ & $\begin{array}{c}\text { Weight } \\
(\mathbf{N})\end{array}$ & $\begin{array}{c}\text { strength } \\
\text { weight }\end{array}$ \\
\hline 1 & Hexagonal & 1.7 & 1.5 & 848.56 & 3.6262 & 234.01 \\
\hline 2 & Circular & 1.7 & 1.5 & 825.34 & 3.5265 & 234.04 \\
\hline 3 & Square & 1.7 & 1.5 & 647 & 3.3691 & 192.04 \\
\hline 4 & Hexagonal & 1.6 & 1.5 & 817.22 & 3.5647 & 229.25 \\
\hline 5 & Circular & 1.6 & 1.5 & 795.48 & 3.4551 & 230.23 \\
\hline 6 & Square & 1.6 & 1.5 & 613.12 & 3.2746 & 187.24 \\
\hline 7 & Hexagonal & 1.5 & 1.5 & 782.79 & 3.4906 & 224.26 \\
\hline 8 & Circular & 1.5 & 1.5 & 752.94 & 3.3626 & 223.92 \\
\hline 9 & Square & 1.5 & 1.5 & 580 & 3.1605 & 183.52 \\
\hline 10 & Hexagonal & 1.7 & 1.4 & 866.9 & 3.6262 & 239.07 \\
\hline 11 & Circular & 1.7 & 1.4 & 835.92 & 3.5265 & 237.04 \\
\hline 12 & Square & 1.7 & 1.4 & 730.33 & 3.3691 & 216.77 \\
\hline 13 & Hexagonal & 1.6 & 1.4 & 835.57 & 3.5647 & 234.40 \\
\hline 14 & Circular & 1.6 & 1.4 & 805.85 & 3.4551 & 233.23 \\
\hline 15 & Square & 1.6 & 1.4 & 689.51 & 3.2746 & 210.56 \\
\hline 16 & Hexagonal & 1.5 & 1.4 & 806 & 3.4906 & 230.91 \\
\hline 17 & Circular & 1.5 & 1.4 & 774.01 & 3.3626 & 230.18 \\
\hline 18 & Square & 1.5 & 1.4 & 647.1 & 3.1605 & 204.75 \\
\hline 19 & Hexagonal & 1.7 & 1.3 & 880.27 & 3.6262 & 242.75 \\
\hline 20 & Circular & 1.7 & 1.3 & 848 & 3.5265 & 240.47 \\
\hline 21 & Square & 1.7 & 1.3 & 763.67 & 3.3691 & 226.67 \\
\hline 22 & Hexagonal & 1.6 & 1.3 & 848.5 & 3.5647 & 238.03 \\
\hline 23 & Circular & 1.6 & 1.3 & 820.4 & 3.4551 & 237.45 \\
\hline 24 & Square & 1.6 & 1.3 & 721.24 & 3.2746 & 220.25 \\
\hline 25 & Hexagonal & 1.5 & 1.3 & 816.66 & 3.4906 & 233.96 \\
\hline 26 & Circular & 1.5 & 1.3 & 784.87 & 3.3626 & 233.41 \\
\hline 27 & Square & 1.5 & 1.3 & 678.95 & 3.1605 & 214.82 \\
\hline & & & & & & \\
\hline
\end{tabular}




\section{Taguchi and ANOVA results}

The orthogonal array and values of $\mathrm{S} / \mathrm{N}$ were shown in Table VII and Results of the mean based on $\mathrm{S} / \mathrm{N}$ were presented in Table 8 and Figure 14:

TABLE VII: $\quad$ Orthogonal array and S/N

\begin{tabular}{|c|c|c|c|c|c|}
\hline $\begin{array}{c}\text { No. of } \\
\text { test }\end{array}$ & $\begin{array}{c}\text { Shape of } \\
\text { holes } \\
\text {-A- }\end{array}$ & $\begin{array}{c}\text { Opening } \\
\text { ratio } \\
\left(D / D_{\boldsymbol{o}}\right) \\
\text {-B- }\end{array}$ & $\begin{array}{c}\text { Spacing } \\
\text { ratio } \\
\left(\boldsymbol{S} / \boldsymbol{D}_{\boldsymbol{o}}\right) \\
\text {-C- }\end{array}$ & $\frac{\text { strength }}{\text { weight }}$ & $\mathbf{S} / \mathbf{N}$ \\
\hline 1 & Hexagonal & 1.7 & 1.5 & 234.01 & 47.38 \\
\hline 2 & Circular & 1.7 & 1.5 & 234.04 & 47.39 \\
\hline 3 & Square & 1.7 & 1.5 & 192.04 & 45.67 \\
\hline 4 & Hexagonal & 1.6 & 1.5 & 229.25 & 47.21 \\
\hline 5 & Circular & 1.6 & 1.5 & 230.23 & 47.24 \\
\hline 6 & Square & 1.6 & 1.5 & 187.24 & 45.45 \\
\hline 7 & Hexagonal & 1.5 & 1.5 & 224.26 & 47.01 \\
\hline 8 & Circular & 1.5 & 1.5 & 223.92 & 47.00 \\
\hline 9 & Square & 1.5 & 1.5 & 183.52 & 45.27 \\
\hline 10 & Hexagonal & 1.7 & 1.4 & 239.07 & 47.57 \\
\hline 11 & Circular & 1.7 & 1.4 & 237.04 & 47.50 \\
\hline 12 & Square & 1.7 & 1.4 & 216.77 & 46.72 \\
\hline 13 & Hexagonal & 1.6 & 1.4 & 234.40 & 47.40 \\
\hline 14 & Circular & 1.6 & 1.4 & 233.23 & 47.36 \\
\hline 15 & Square & 1.6 & 1.4 & 210.56 & 46.47 \\
\hline 16 & Hexagonal & 1.5 & 1.4 & 230.91 & 47.27 \\
\hline 17 & Circular & 1.5 & 1.4 & 230.18 & 47.24 \\
\hline 18 & Square & 1.5 & 1.4 & 204.75 & 46.22 \\
\hline 19 & Hexagonal & 1.7 & 1.3 & 242.75 & 47.70 \\
\hline 20 & Circular & 1.7 & 1.3 & 240.47 & 47.62 \\
\hline 21 & Square & 1.7 & 1.3 & 226.67 & 47.11 \\
\hline 22 & Hexagonal & 1.6 & 1.3 & 238.03 & 47.53 \\
\hline 23 & Circular & 1.6 & 1.3 & 237.45 & 47.51 \\
\hline 24 & Square & 1.6 & 1.3 & 220.25 & 46.86 \\
\hline 25 & Hexagonal & 1.5 & 1.3 & 233.96 & 47.38 \\
\hline 26 & Circular & 1.5 & 1.3 & 233.41 & 47.36 \\
\hline 27 & Square & 1.5 & 1.3 & 214.82 & 46.64 \\
\hline
\end{tabular}

From Table VIII and Figure 15 it was seen that the optimum set of levels is (A1 B1 C3) which gives the best ultimate strength and best strength to weight ratio. The combination of parameters is the hexagonal hole shape, $D / D_{o}=1.7$ and $S / D_{o}=1.3$. Delta column refers to the difference between the maximum and minimum level values. It shows that the shape of holes has more effect on buckling strength than the other parameters.

TABLE VIII: $\quad$ The analysis of mean results based on $\mathrm{S} / \mathrm{N}$

\begin{tabular}{ccccccc}
\hline \hline symbols & parameters & Level 1 & Level 2 & Level 3 & Delta & Rank \\
\hline $\mathrm{A}$ & Shape of holes & 47.385 & 47.358 & 46.268 & 1.117 & 1 \\
\hline $\mathrm{B}$ & $D / D_{O}$ & 47.184 & 47.002 & 46.823 & 0.361 & 3 \\
\hline $\mathrm{C}$ & $S / D_{O}$ & 46.625 & 47.083 & 47.302 & 0.677 & 2 \\
\hline
\end{tabular}




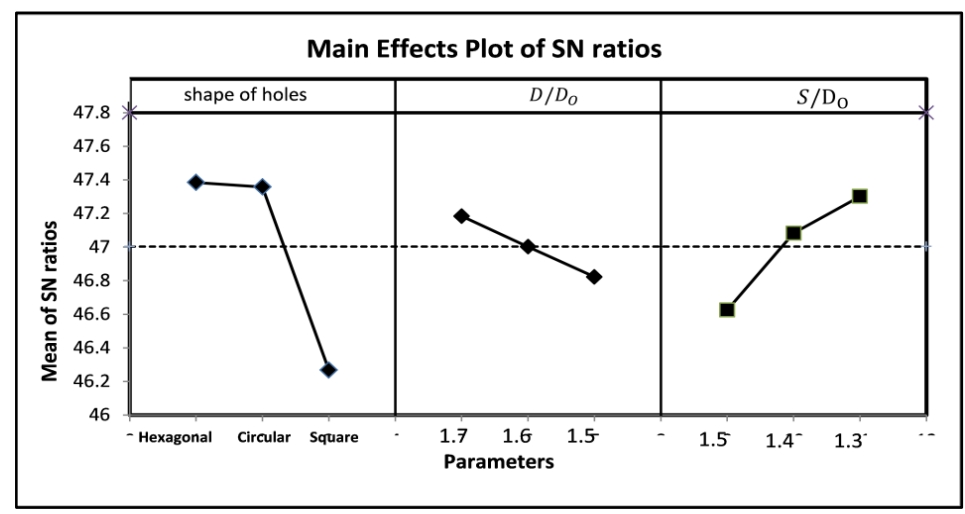

Figure 15: The parameters $-\mathrm{S} / \mathrm{N}$ curves

Table IX shows the results of ANOVA. These results represent the importance and contribution of parameters as a percentage. The shape of holes has the highest contribution $(64.24 \%)$ and the lowest effect is the opening ratio $(5.14 \%)$.

TABLE IX:Results of (ANOVA)

\begin{tabular}{ccccccc}
\hline \hline \multicolumn{2}{c}{ Source } & Sum sq. & d.o.f. & Mean sq. & F & P \% \\
\hline A & Shape & 7.310 & 2 & 3.655 & 54.55 & 64.24 \\
\hline B & $D / D o$ & 0.585 & 2 & 0.293 & 4.37 & 5.14 \\
\hline C & $S / D o$ & 2.149 & 2 & 1.075 & 16.04 & 18.89 \\
\hline Error & 1.334 & 20 & 0.067 & & \\
\hline Total & 11.379 & 26 & & & \\
\hline
\end{tabular}

\section{CONCLUSION}

In the current study, a finite element method was implemented to investigate the buckling behavior of perforated thin-walled lipped beams under a combined load. The finite element models were validated by experimental experiences. Three variables namely shape of holes, opening ratio $D / D_{o}$ and the spacing ratio of $S / D_{o}$ were considered to identify the optimum combination set of parameters for the best critical load value. It has been concluded that the presence of holes on the web of the hipped channel beams had a significant effect on their buckling strengths. It was found that the hexagonal hole shape causes a less decrease in buckling load compared with the other hole shapes whereas the square hole shape had the worst buckling strength. Results showed that the combination of parameters that gives the best buckling strength is the hexagonal hole shape, $D / D_{o}=$ 1.7 and $S / D_{o}=1.3$ and the shape of holes has more effect than the other factors on buckling behavior. Taguchi and ANOVA methods were implemented to confirm the effect of parameters and their combinations.

\section{References}

[1] C. D. Moen and B. W. Schafer, Impact of holes on the elastic buckling of cold- formed steel columns, Int. Spec. Conf. Cold-Formed Steel Struct., (2006) 269-283.

[2] C. D. Moen and B. W. Schafer, Experiments on cold-formed steel columns with holes, Thin-Walled Struct., 46(2008) 1164-1182. https://doi.org/10.1016/j.tws.2008.01.021

[3] C. D. Moen, M. Asce, B. W. Schafer, and M. Asce, Direct Strength Method for Design of Cold-Formed Steel Columns with Holes, J. Struct. Eng., 137(2011) 559-570. http://dx.doi.org/10.1061/(ASCE)ST.1943$\underline{541 X .0000310}$

[4] F. Zhou and B. Young, Web crippling of aluminium tubes with perforated webs, Eng. Struct., 32(2010) 1397-1410. https://doi.org/10.1016/j.engstruct.2010.01.018

[5] M. P. Kulatunga and M. Macdonald, Investigation of cold-formed steel structural members with perforations of different arrangements subjected to compression loading, Thin-Walled Struct., 67(2013) 7887. https://doi.org/10.1016/j.tws.2013.02.014 
[6] M. P. Kulatunga, M. Macdonald, J. Rhodes, and D. K. Harrison, Load capacity of cold-formed column members of lipped channel cross-section with perforations subjected to compression loading - Part I: FE simulation and test results, Thin-Walled Struct., 80(2014)1-12. https://doi.org/10.1016/j.tws.2014.02.017

[7] M. Macdonald and M. P. Kulatunga, The effects of end conditions on the load capacity of cold- formed steel column members of lipped channel cross- section with perforations subjected to compression loading, 22nd Int. Spec. Conf. Recent Res. Dev. Cold-Formed Steel Des. Constr., (2014)129-142.

[8] M. Macdonald, M. Kulatunga, and M. Kotełko, The effects of compression loading on perforated coldformed thin-walled steel structural members of lipped-channel cross-section, AIP Conf. Proc., 2060(2019)112. https://doi.org/10.1063/1.5086138

[9] R. Feng, B. Young, and M. Asce, Experimental Investigation of Aluminum Alloy Stub Columns with Circular Openings, J. Struct. Eng., 141(2015) 1-10. https://doi.org/10.1061/(ASCE)ST.1943-541X.0001265

[10] P. I. G. Bhavi, Experimental and FEA comparison of cold formed stainless steel and aluminium alloy having perforation of various combinations subjected to buckling load, Int. J. Eng. Innov. Res., 4(2015) 573-580.

[11] R. Feng, W. Zhu, H. Wan, A. Chen, and Y. Chen, Tests of perforated aluminium alloy SHSs and RHSs under axial compression, Thin-Walled Struct., $130 \quad$ (2018) 194-212. http://dx.doi.org/10.1016/j.tws.2018.03.017

[12] F. P. V. Ferreira and C. H. Martins, LRFD for Lateral-torsional buckling resistance of cellular beams, Int. J. Civ. Eng., 18(2019)303-323. http://dx.doi.org/10.1007/s40999-019-00474-7

[13] F. P. V. Ferreira, A. Rossi, and C. H. Martins, Lateral-torsional buckling of cellular beams according to the possible updating of EC3, J. Constr. Steel Res., $153 \quad$ (2019) 222-242. http://dx.doi.org/10.1016/j.jcsr.2018.10.011

[14] S. G. Morkhade and L. M. Gupta, Behavior of Castellated Steel Beams : State of the Art Review, no. April, 2020.

[15] R. Shamass and F. Guarracino, Numerical and analytical analyses of high-strength steel cellular beams: A discerning approach, J. Constr. Steel Res., 166(2020)105911. https://doi.org/10.1016/j.jcsr.2019.105911

[16] Tuğrul BÖLÜKBAŞ and Osman Hamdi METE, A buckling behavior of elliptic perforated steel CHS columns exposed to axial compression load, Lat. Am. J. Solids Struct., 17(2020)1-17. https://doi.org/10.1590/1679-78255908

[17] A. Bahrami and M. Najarnasab, Ultimate Behaviour of Perforated Steel Plate Girders Subjected to Shear Loading, Open Constr. Build. Technol. J., 14(2020)70-83. https://doi.org/10.2174/1874836802014010070

[18] G. J. White, R. H. Grzebieta, and N. W. Murray, Maximum strength of square thin-walled sections subjected to combined loading of torsion and bending, Int. J. Impact Eng., 13(1993)203-214. https://doi.org/10.1016/0734-743X(93)90093-M

[19] F. Mohri, C. Bouzerira, and M. Potier-Ferry, Lateral buckling of thin-walled beam-column elements under combined axial and bending loads, Thin-Walled Struct., 46(2008) 290-302. https://doi.org/10.1016/J.TWS.2007.07.017

[20] S. S. Cheng, B. Kim, and L. Y. Li, Lateral-torsional buckling of cold-formed channel sections subject to combined compression and bending, J. Constr. Steel Res., 80(2013) 174-180. http://dx.doi.org/10.1016/j.jesr.2012.07.026

[21] A. Khamlichi, J. El Bahaoui, L. El Bakkali, M. Bezzazi, and A. Limam, Effect of two interacting localized defects on the critical load for thin cylindrical shells under axial compression, Am. J. Eng. Appl. Sci., 3(2010)464-469. https://doi.org/10.3844/ajeassp.2010.464.469

[22] A. Khamlichi and A. Limam, Assessing the effect of two entering triangular initial geometric imperfections on the buckling strength of an axisymmetric shell subjected to uniform axial compression, Civil-Comp Proc., 99(2012) 1-11. http://dx.doi.org/10.4203/ccp.99.166

[23] R. Azadi and Y. Rostamiyan, Experimental and analytical study of buckling strength of new quaternary hybrid nanocomposite using Taguchi method for optimization, Constr. Build. Mater., 88(2015)212-224. http://dx.doi.org/10.1016/j.conbuildmat.2015.04.018

[24] J. C. Lin and K. Lee, Optimization of bending process parameters for seamless tubes using Taguchi method and finite element method, Adv. Mater. Sci. Eng., 2015 (2015) 1-8. https://doi.org/10.1155/2015/730640 
[25] M. J. Soufain, S. J. Sujavandi, U. A. Shariff, and N. S. Kumar, Analytical investigation for buckling capacity of composite steel tubes under compression - Taguchi' s approach using Minitab-16, Int. J. innvative Res. Sci. Eng. Technol., 6 (2017) 6645-6655. https://doi.org/10.15680/IJIRSET.2017.0604079

[26] H. M.AL-khafaji, Best level of parameters for a critical buckling load for circular thin- walled structure subjected to bending, Al-Khwarizmi Eng. J., 13(2017) 12-21. https://doi.org/10.22153/kej.2017.07.003

[27] Ranjit Roy, A primer on the Taguchi method, 1st Editio. New York: society of manufacturing and engineers, 1990.

[28] Kabe and Gupta, Experimental Design; Exercises Solutions. New York: Springer, 2006.

[29] A. International, B $557 \mathrm{M}$ - 02a: Standard test methods of tension testing wrought and cast aluminum- and magnesium-alloy products [metric], 03(2003).

[30] CEN, EN1993-1-3 Eurocode 3: Design of steel structures - part 1-3: supplementary rules for cold-formed members and sheeting, in European Committee for Standardization, Brussels, 2006.

[31] Steelwork design guide to BS 5950-1: 2000 7th edition, in The Steel Construction Institute and The British Constructional Steelwork Association Limited, 1(2000).

[32] E. Madenci and I. Guven, The finite element method and applications in engineering using ANSYS. the university of Arizona, 2006. 